\title{
Controle biológico de antracnose em pós-colheita de banana "Maçã" com Saccharomyces spp.
}

\author{
Anderson Luis Heling ${ }^{1}$; Odair José Kuhn ${ }^{1}$; José Renato Stangarlin ${ }^{1}$; Nicanor Pilarski Henkemeier ${ }^{1}$; Sidiane Coltro- \\ Roncato $^{1}$; Edilaine Della Valentina Gonçalves ${ }^{1}$
}

${ }^{1}$ Universidade Estadual do Oeste do Paraná, Campus Marechal Cândido Rondon, Rua Pernambuco, 1777, CEP 85960-000, Marechal Cândido

Rondon, Paraná.

Autor para correspondência: Anderson Luis Heling (andersonlheling@gmail.com)

Data de chegada: 19/06/2015. Aceito para publicação em: 21/07/2016.

$10.1590 / 0100-5405 / 2105$

\section{RESUMO}

Heling, A.L.; Kuhn, O.J.; Stangarlin, J.R.; Henkemeier, N.P.; Coltro-Roncato, S.; Gonçalves, E.D.V. Controle biológico de antracnose em póscolheita de banana "Maçã" com Saccharomyces spp. Summa Phytopathologica, v.43, n.1, p.49-51, 2017.

Este trabalho objetivou analisar o controle biológico do Colletotrichum musae em bananas por meio de Saccharomyces cerevisiae e Saccharomyces boulardii. Células de S. cerevisiae foram obtidas a partir do fermento de panificação Fleischmann ${ }^{\circledR}$. Células de S. boulardii foram obtidas a partir do medicamento Floratil ${ }^{\circledR}$. Utilizou-se um cacho de banana colhido de área orgânica, os frutos passaram por um processo de assepsia, em seguida foram tratados com células de $S$. cerevisiae, $S$. boulardii e ambas as leveduras na concentração de $2 \mathrm{~g} \mathrm{~L}^{-1}$, após 24 horas inoculou-se o C. musae em três pontos por fruto. Para avaliar-se o efeito da concentração de células no tratamento o processo foi repetido, tratando-se os frutos com concentrações de $0 ; 0,5 ; 1 ; 2 ; 4$ e $8 \mathrm{~g} \mathrm{~L}^{-1}$ de
S. cerevisiae e $S$. boulardii, avaliou-se a área lesionada, a cada 48 horas, por 14 dias. Também avaliou-se o halo de inibição e a produção de compostos voláteis, ambos in vitro, para analisar se há ocorrência de antagonismo. Observou-se que o tratamento com as leveduras reduz o progresso da doença, e que $S$. cerevisiae e S. boulardii apresentam maior eficiência na concentração de 5,5 e $6,3 \mathrm{~g} \mathrm{~L}^{-1}$, respectivamente, apresentando redução de $48 \%$ e $35 \%$ do progresso da doença, respectivamente. Observou-se a formação de halo de inibição e produção de compostos voláteis, indicando que estas leveduras atuam por meio de antagonismo. Deste modo, estas leveduras são potencias agentes de controle biológico do C. musae.

Palavras-chave: Colletotrichum musae; Saccharomyces boulardii; Saccharomyces cerevisiae.

\section{ABSTRACT}

Heling, A.L.; Kuhn, O.J.; Stangarlin, J.R.; Henkemeier, N.P.; Coltro-Roncato, S.; Gonçalves, E.D.V. Biological control of anthracnose in the postharvest of manzano bananas using Saccharomyces spp. Summa Phytopathologica, v.43, n.1, p.49-51, 2017.

This study aimed to analyze the biological control of Colletotrichum musae in bananas by using Saccharomyces cerevisiae and Saccharomyces boulardii. Cells of $S$. cerevisiae were obtained from Fleischmann ${ }^{\circledR}$ bread yeast. Cells of $S$. boulardii were obtained from the drug Floratil ${ }^{\circledR}$. A bunch of bananas collected from an organic area was used. Fruits underwent a process of asepsis and were then treated with cells of $S$. cerevisiae, S. boulardii and both yeasts at the concentration of $2 \mathrm{~g} \mathrm{~L}^{-1}$; after 24 hours, C. musae was inoculated in three points per fruit. To evaluate the effect of cell concentration on the treatment, the process was repeated, treating the fruits with concentrations of $0 ; 0.5 ; 1 ; 2$;
4 and $8 \mathrm{~g} \mathrm{~L}^{-1}$ of S. cerevisiae and S. boulardii; the injured area was evaluated at every 48 hours during 14 days. The inhibition halo and the production of volatile compounds were also evaluated, in vitro, to analyze whether there is antagonism. Treatment with these yeasts reduces the disease progress and $S$. cerevisiae and $S$. boulardii exhibit greater efficiency at the concentration of 5.5 and $6.3 \mathrm{~g} \mathrm{~L}^{-1}$, respectively, leading to a reduction of $48 \%$ and $35 \%$ in the disease progress, respectively. We observed formation of inhibition halo and production of volatile compounds, indicating that these yeasts act by means of antagonism. Thus, these yeasts are potential agents for the biological control of C. musae.

Keywords: Colletotrichum musae; Saccharomyces boulardii; Saccharomyces cerevisiae.

A antracnose, causada por C. musae é a principal doença em póscolheita da banana, os sintomas caracterizam-se por lesões escuras e deprimidas, que em condições de alta umidade apresentam frutificações rosadas do fungo (1). O controle biológico desta doença é de grande valia, pois apresenta baixo impacto a saúde dos consumidores.

As leveduras apresentam-se como promissores agentes de biocontrole de doenças de plantas, pois são integrantes da microbiota epifítica e endofítica, competindo com os agentes patogênicos (6). Muitos estudos já observaram o efeito das leveduras como agentes de controle biológico, em especial as do gênero Saccharomyces.

Este trabalho objetivou analisar o controle biológico do C. musae em bananas maçã, por meio das leveduras $S$. cerevisiae e $S$. boulardii.

Células de $S$. cerevisiae foram obtidas a partir do fermento de panificação Fleischmann ${ }^{\circledR}$. Células de $S$. boulardii foram obtidas a partir do medicamento Floratil ${ }^{\circledR}$. C. musae foi isolados a partir de frutos infectados colhidos de área orgânica. Utilizou-se um cacho de banana "maçã”, colhido de área orgânica, situada na latitude 24³1'57”S e longitude $54^{\circ} 01$ ' 15 'O. Os frutos passaram por um processo de assepsia, com álcool $70 \%$ por 30 segundos e hipoclorito de sódio $1 \%$ por dois minutos, sendo posteriormente lavados com água destilada e acondicionados em caixas plásticas do tipo gerbox.

Utilizou-se o delineamento experimental inteiramente casualizado (DIC), contendo quatro tratamentos e cinco repetições, cada parcela experimental foi constituída por uma caixa contendo um fruto. Os tratamentos empregados foram $S$. cerevisiae, $S$. boulardii, ambas as leveduras e testemunha, a qual tratou-se apenas com água destilada. As leveduras para tratamento foram previamente cultivadas em caldo YEPG. Para tratamento dos frutos, estes foram imersos em suspensão 
de células em água destilada na concentração de $2 \mathrm{~g} \mathrm{~L}^{-1}$, por um período de duas horas. A inoculação do patógeno foi realizada 24 horas após o tratamento, com $100 \mu \mathrm{L}$ de inóculo na concentração de $10^{4}$ conídios $\mathrm{mL}^{-1}$, inoculando-se em ferimentos previamente realizados com agulha de $3 \mathrm{~mm}$ de diâmetro, sendo efetuada inoculação em três pontos por fruto.

Avaliou-se a área lesionada pela mensuração de dois diâmetros perpendiculares de cada lesão com auxílio de paquímetro. Esta avaliação foi realizada a cada 48 horas, por um período de 14 dias, mantendo os frutos em caixas plásticas e em temperatura ambiente. Com estes valores calculou-se a área abaixo da curva de progresso da doença (AACPD), conforme metodologia de Shaner \& Finney (9).

Para compreender o efeito das concentrações de células das leveduras no tratamento dos frutos de banana foram instalados outros dois experimentos, um com $S$. cerevisiae e outro com $S$. boulardii. Os tratamentos testados foram concentrações de $0 ; 0,5$; 1; 2; 4 e $8 \mathrm{~g} \mathrm{~L}^{-1}$ das leveduras, contendo quatro repetições, a parcela experimental constituiu-se de um fruto com três lesões. Os demais procedimentos e avaliações foram realizados conforme descritos no experimento anterior.

A fim de analisar se há ocorrência de antagonismo, foram montados ensaios in vitro para avaliar a presença de halo de inibição (H.I.) e a produção de compostos voláteis (C.Vol.). Estes ensaios tiveram delineamento inteiramente casualizados, com quatro tratamentos e cinco repetições, cada placa de Petri $(9,5 \mathrm{~cm}$ de diâmetro) constituiu uma parcela experimental. Os tratamentos testados foram $S$. cerevisiae, S. boulardii; Controle (Azoxistrobina + Ciproconazole) e Testemunha (água destilada).

Para avaliação do H.I. os tratamentos foram aplicados com alça de platina em uma das extremidades da placa de Petri com meio Ágar-YEPG, à $1 \mathrm{~cm}$ da borda, na outra extremidade, à $1 \mathrm{~cm}$ da borda, repicou-se um disco com $5 \mathrm{~mm}$ de diâmetro do C. musae. Estas placas ficaram vedadas e armazenadas em BOD a $27^{\circ} \mathrm{C}$ por 16 dias, quando então avaliou-se o H.I. mensurando-se a maior e a menor distância entre as colônias do tratamento e do patógeno, sendo considerado o H.I. a média destas medidas.

Os C.Vol. foram avaliados aplicando-se os tratamentos em placas com Ágar-YEPG. No centro de placas com BDA repicou-se um disco de $5 \mathrm{~mm}$ de diâmetro de C. musae. As placas com os tratamentos foram fechadas na parte superior com as placas com o patógeno, ficando invertidas. Estas placas ficaram vedadas e armazenadas em BOD a 27 ${ }^{\circ} \mathrm{C}$ por 7 dias. Após este período determinou-se o número de conídios de C. musae por placa, esta determinação foi efetuada em câmara de Neubauer.

Os resultados foram submetidos a análise de variância. Os experimentos com concentrações de células de leveduras foram submetidos a análise de regressão, os demais foram submetidos ao teste de médias de Tukey ao nível de 5\% de significância.

Observou-se que os frutos tratados com as leveduras na concentração de $2 \mathrm{~g} \mathrm{~L}^{-1}$ apresentaram redução da AACPD, reduzindo assim a área lesionada pelo patógeno, conforme Tabela 1, sendo as maiores reduções observadas nos frutos tratados com $S$. cerevisiae e ambas as leveduras, demonstrando a eficiência da $S$. cerevisiae no controle do C. musae em frutos de banana. Diversas leveduras são

Tabela 1. Área abaixo da curva de progresso da doença (AACPD) de frutos de banana maçã, tratados com leveduras; Halo de inibição (H.I.) entre leveduras e C. musae avaliado in vitro; e número de conídios de C. musae por placa de Petri, sobre o efeito dos compostos voláteis de leveduras do gênero Saccharomyces

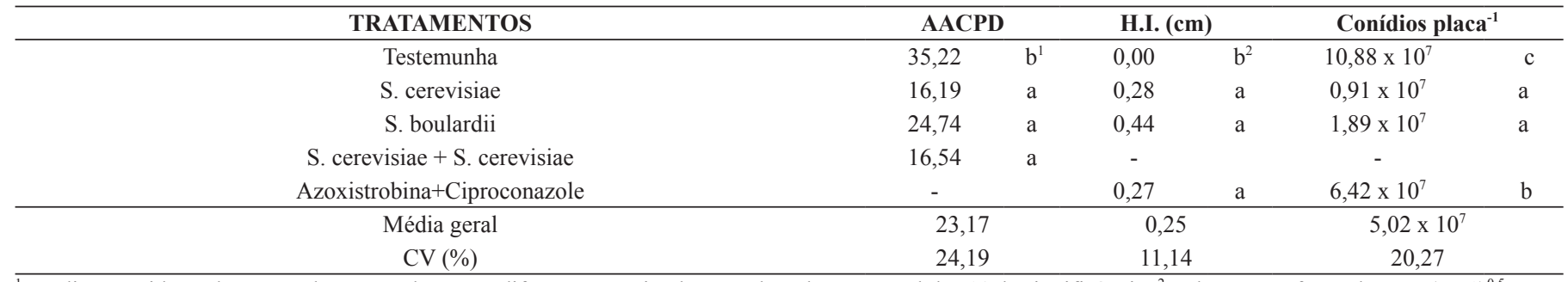

${ }^{1}$ Médias seguidas pela mesma letra na coluna não diferem entre si pelo teste de Tukey ao nível de $5 \%$ de significância. ${ }^{2}$ Valores transformados por $(\mathrm{X}+1)^{0,5}$.

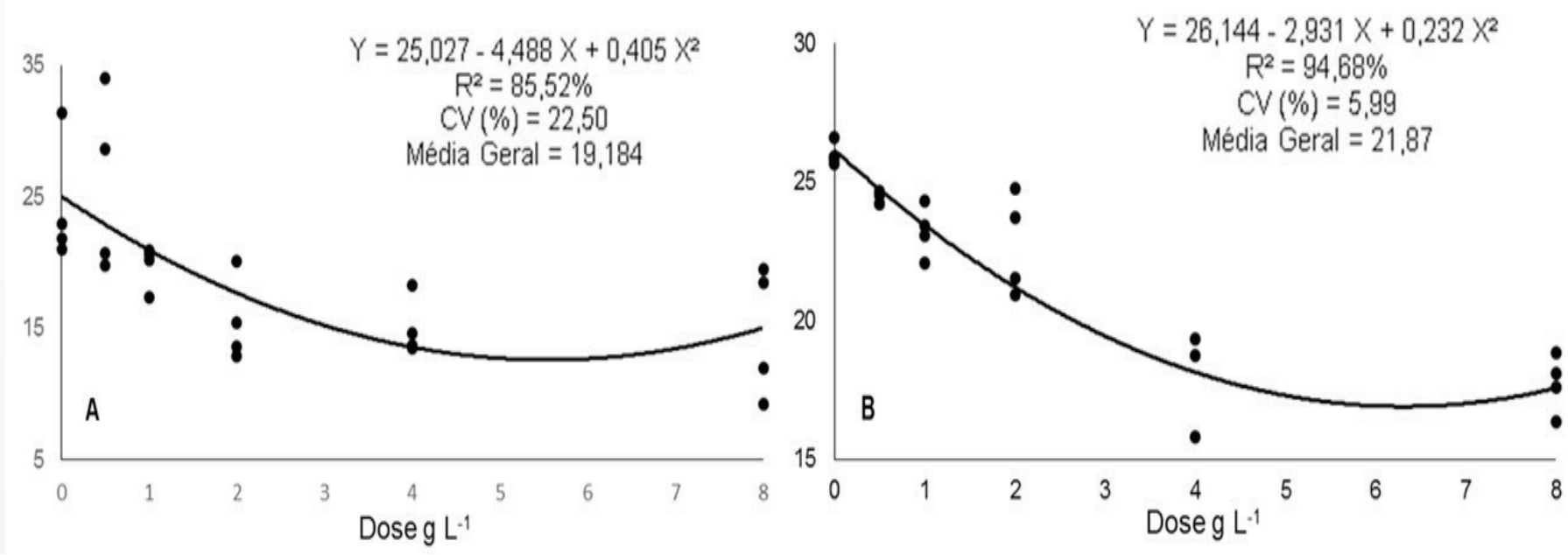

Figura 1. A) Área abaixo da curva de progresso da doença (AACPD) para antracnose, causada por Colletotrichum musae, em frutos de banana maçã, tratados com Saccharomyces cerevisiae em diferentes concentrações $\left(0 ; 0,5 ; 1 ; 2 ; 4 \mathrm{e} 8 \mathrm{~g} \mathrm{~L}^{-1}\right)$. B) AACPD para antracnose, causada por $C$. musae, em frutos de banana, tratados com Saccharomyces boulardii em diferentes concentrações $\left(0 ; 0,5 ; 1 ; 2 ; 4\right.$ e $\left.8 \mathrm{~g} \mathrm{~L}^{-1}\right)$. 
estudadas como agentes de controle biológico de doenças, França et al. (3), observaram que lesões de antracnose em frutos de pimentão, causado por Colletotrichum gloeosporioides, foram reduzidas com o uso das leveduras Rhodotorula glutinis e Rhodotorula aurantiaca.

Com a elevação na concentração de $S$. cerevisiae até 5,5 $\mathrm{gL}^{-1}$ no tratamento dos frutos, há redução na AACPD em $48 \%$, consequentemente, este ponto apresenta menor dano patogênico (Figura 1A). A concentração das leveduras na calda de tratamento é de grande relevância para se observar o efeito do controle biológico, no entanto há poucos estudos relacionando o efeito da concentração no manejo do patógeno. Piccinin et al. (8), observaram que a concentração de $25 \mathrm{~g} \mathrm{~L}^{-1}$ de $S$. cerevisiae apresentou controle de outra espécie do gênero Colletotrichum, na cultura do sorgo, trata-se do Colletotrichum sublineolum. No entanto Hoffmann et al. (5) observaram que em concentração menor $\left(2 \mathrm{~g} \mathrm{~L}^{-1}\right) S$. cerevisiae controlou o crestamento bacteriano comum na cultura do feijoeiro.

Para o tratamento com células de $S$. boulardii, observa-se que o ponto de máxima eficiência na redução da lesão é a concentração de $6,3 \mathrm{~g} \mathrm{~L}^{-1}$, onde há uma redução de $35 \%$ da AACPD (Figura 1B). Müller (7), não obteve controle do crestamento bacteriano comum com a utilização desta levedura, no entanto este utilizou concentrações baixas quando comparadas com este estudo, a maior concentração utilizada pelo autor foi de $0,125 \mathrm{~g} \mathrm{~L}^{-1}$, Heling et al. (4) utilizando concentração de $2 \mathrm{~g} \mathrm{~L}^{-1}$ na cultura do morangueiro, também não obtiveram eficiência no controle de Mycosphaerella fragarie. Deste modo, pode-se inferir que esta levedura apresenta eficiência de controle em concentrações mais elevadas, como a observada neste estudo.

Com valores expressivos na redução de antracnose em frutos de banana em pós-colheita, torna-se necessário maiores estudos para entendimento de como estes agentes de controle biológico atuam. Houve formação de halo de inibição para todos os tratamentos testados (Tabela 1), deste modo, as leveduras testada produzem metabólitos com propriedades antagônicas ao C. musae. Também observa-se uma expressiva redução no número de conídios do C. musae por placa, quando realizado o teste de compostos voláteis (Tabela 1), indicando que durante o desenvolvimento as leveduras estudadas liberam compostos voláteis que afetam o desenvolvimento do C. musae, e produção de conídios. Conforme Fialho (2) os compostos voláteis produzidos por S. cerevisiae são constituídos principalmente por álcoois, Toffano (10) identificou estes álcoois como sendo 2-metil-1butanol e 3-metil-1-butanol.

Deste modo, as leveduras $S$. cerevisiae e $S$. boulardii podem ser consideradas como sendo potencias agentes de controle biológico do C. musae em bananas maçã.

\section{AGRADECIMENTOS}

À CAPES pela concessão das bolsas de mestrado e doutorado e ao CNPq pela concessão das bolsas produtividade aos autores.

\section{REFERÊNCIAS}

1. Cordeiro, Z.J.M; Kimati, H. Doenças da bananeira (Musa spp.). In: Kimati, H.; Amorim, L.; Bergamin Filho, A.; Camargo, L.E.A.; Rezende, J.A.M.; (Ed.). Manual de fitopatologia: doenças de plantas cultivadas. 4.ed. São Paulo: Agronômica Ceres, 1997. v.2, cap.13, p.113-135.

2. Fialho, M.B.; Toffano, L.; Pedroso, M.P.; Augusto, F.; Pascholati, S.F. Volatile organic compounds produced by Saccharomyces cerevisiae inhibit the in vitro development of Guignardia citricarpa, the causal agent of citrus black spot. World Journal of Microbiology and Biotechnology, v.26, n.5, p.925-932, 2010.

3. França, G.S.; Carvalho, R.R.C.; Neves, R.P.; Araujo, E.R.; Laranjeira, D. Controle pós-colheita da antracnose do pimentão pela levedura Rhodotorula glutinis. Bioscience Journal, Uberlândia, v.31, n.2, p.451-459, 2015.

4. Heling, A.L.; Kuhn, O.J.; Stangarlin, J.R. Controle biológico de Mycosphaerella fragariae na cultura do morangueiro. Scientia Agraria Paranaensis, Marechal Cândido Rondon, v.14, n.4, p. 221-228, 2015.

5. Hoffmann, M.R.B.; Kuhn, O.J.; Stangarlin, J.R.; Battistus, A.G.; Stülp, J.L.; Meinerz, C.C. Controle do crestamento bacteriano comum por Saccharomyces cerevisiae, Saccharomyces boulardii e óleo essencial de laranja em feijoeiro suscetível e moderadamente resistente. Cultivando o Saber, Cascavel, v.5, n.4, p.8-23, 2012.

6. Mello, M.R.F.; Silveira, E.B.; Viana, I.O.; Guerra, M.L.; Mariano, R.L.R. Uso de antibióticos e leveduras para controle da podridão-mole em couve- chinesa. Horticultura Brasileira, Vitória da Conquista, v.29, n.1, p.78-83. 2011

7. Müller, S.F. Custo adaptativo da indução de resistência por Saccharomyces boulardii em feijoeiro (Phaseolus vulgaris L.). 2011. 43f. Dissertação (Programa de Pós-Graduação em Agronomia) - Universidade Estadual do Oeste do Paraná, Marechal Cândido Rondon.

8. Piccinin, E.; Di Piero, R. M.; Pascholati, S.F. Efeito de Saccharomyces cerevisiae na produtividade de sorgo e na severidade de doenças foliares no campo. Fitopatologia Brasileira, Brasília, DF, v.30, n.1, p.5-9, 2005.

9. Shaner, G.; Finney, R.E. The effect of nitrogen fertilization on the expression of slow-mildewing resistence in knox wheat. Phytopathology, Saint Paul, v.67, p.1051-1056, 1977.

10. Toffano, L. Efeito dos extratos do albedo de Citrus sinensis, Lentinula edodes, Agaricus blazei e dos compostos orgânicos voláteis produzidos por Saccharomyces cerevisiae no controle da mancha preta dos citros. 2010. 78f. Tese (Doutorado em Fitopatologia) - Escola Superior de Agricultura "Luiz de Queiroz", Universidade de São Paulo, Piracicaba. 